INTERNATIONAL JOURNAL OF

MULTIDISCIPLINARY STUDIES IN ARCHITECTURE

AND CULTURAL HERITAGE

\title{
A Plan to Document and Treatment an Archaeological Pottery Amphora from Early Dynastic - Helwan Cemetery
}

\author{
Elshaimaa Abd elrahim Abd elrahman a, *, Magda Mohamed Saleh b \\ a Lecturer, Conservation Department, Faculty of Archaeology, Cairo University, Egypt \\ b Director of Archaeological Restoration of Helwan
}

\begin{abstract}
This research is concerned with putting a plan for documenting and treating an Archaeological pottery Amphorae, dating back to Early Dynastic. It was discovered in Helwan Cemetery, which is considered one of the most important Archaeological sites in Egypt, and has not yet revealed all its secrets. The pottery Amphorae was exposed to physical and chemical damage during burial and after excavation, from interactions with various damage factors.

The damage extent after excavation has varied between the effect of the burial residues inside and outside the Amphorae, the cracks in the thickness of the body showing, clearly, in addition to the effect of high relative humidity with high temperature degrees on the crystallization of salts on the internal and external surface and between the crystals of the body which led to crusting and flaking off the surface.

The components of the damaged pottery Amphorae will be identified through the use of different methods of documentation such as AutoCAD and other methods, and then the appropriate examination and analysis methods to identify the damage products, and then choice the treatment plan, using the Digital Optical Microscope, the Scanning Electron Microscope with the energy dispersion unit SEM-EDX, X-Ray Diffraction (XRD) to identify the crystallized mineral compounds to the body or deteriorate products, as well as differential thermal analysis (DTA) to determine the approximate firing degree, because they have an important role in determining the steps and the materials of treatment. It is recommended through this study that the treatment plan is suitable for the conditions in which the Amphorae will be present, whether it will be in storage or exhibition environment.
\end{abstract}

\begin{tabular}{ll}
\hline Keywords & \\
- & Helwan Cemetery. \\
- & Amphorae. \\
- & Encrustation. \\
- & Orifice. \\
- & Good Polishing
\end{tabular}

\section{Introduction}


Helwan Cemetery one of the most important Archaeological sites in Egypt, itlocates in medium place between North and South, still needs more studies to reveal more of its secrets.

the purpose of this study to put an appropriate plan to document and treatment an Archaeological pottery Amphorae from this site, through important steps as; different documentation and analytical methods to identify the damage products, and then choice the best treatment steps for cleaning, salts removing, replacement, consolidation and any step which the Archaeological pottery Amphorae is need.

\section{2- Experimental procedure (Plane of document and treatment):}

\section{2-1 Selection the Pottery object}

One Archaeological pottery Amphorae was excavated and chosen from Helwan Cemetery in 2003, and have been stored in Helwan artifact store since that time till now. It affected and attacked by various environmental deteriorate factors, causing many cracks, encrustation and efflorescence of salts, and sediment of dust and dirt on its surface. Following the Plane of document and treatment the Archaeological pottery Amphorae:

\section{$\underline{\text { 2-2 }}$ Documentation}

\section{A-Visual investigation}


Visual investigation is important because the Amphorae required different special different analytical approaches to get full record (A Standard for Pottery Analysis in Archaeology, 2015), besides use different measuring tools like Countor Gague and Pockles to accurate measuring.

It is a dark reddish brown color pottery Amphorae, return to Early Dynastic period, it is documentation number is $860 / 98$, it is a store pot, and was used tosave and store wine or perfume, the dimension of it as in the following table:

Table no.1

\begin{tabular}{|c|c|}
\hline The dimensions & The measurements \\
\hline The total height & $70 \mathrm{~cm}$ \\
Orifice dropping & $12 \mathrm{~cm}$ \\
Orifice thickness & $1.5 \mathrm{~cm}$ \\
Base dropping diameter & $5.5 \mathrm{~cm}$ \\
The largest width & $74 \mathrm{~cm}$ \\
The vessel thickness & $1.5 \mathrm{~cm}$ \\
\hline
\end{tabular}

It has a short neck with a medium thick rim - it is without handles and it has medium coarse or roughness texture, it is hand mad with 
medium thick walls in good polishing, it has a narrow base (Pic.No. $1,2,3,4,5)$ these features and deteriorate aspects appeared by visual investigation.
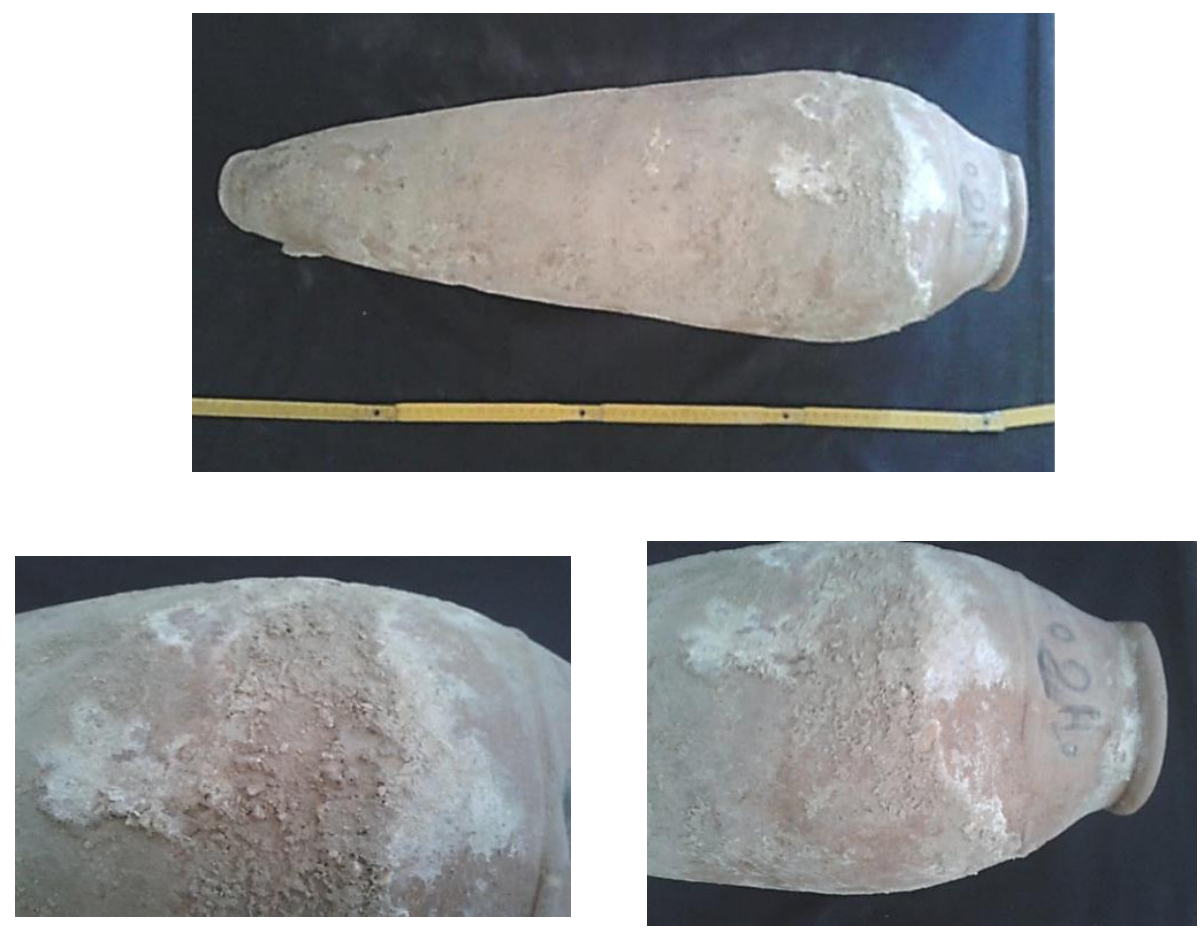


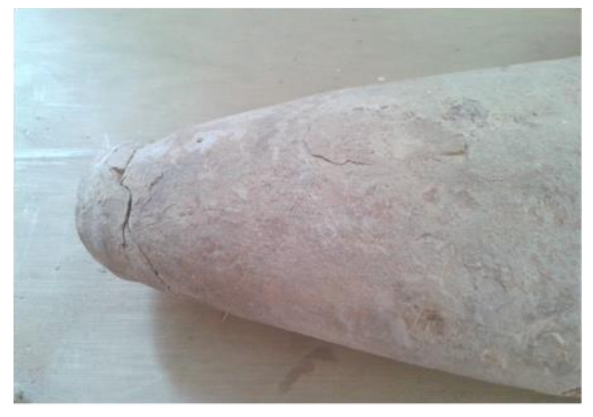

Pic. No. $1,2,3,4,5$ show the Archaeological Pottery Amphorae of the study, in details

\section{B-AutoCAD}

It is very important method to document artifacts, and Archaeological investigations, it considers graphic documentation, especially the Pottery and Ceramic objects. Used to draw the actual matter or state as it is in the naturein all details, and document the deterioration feature on the draw like cracks, salt crystal, missing parts. This method explains the object details (Buna, Z., 2014).

The Archaeological pottery Amphorae was documented and draw by AutoCAD method, which record the deterioration features on it (fig no.1a,b) 

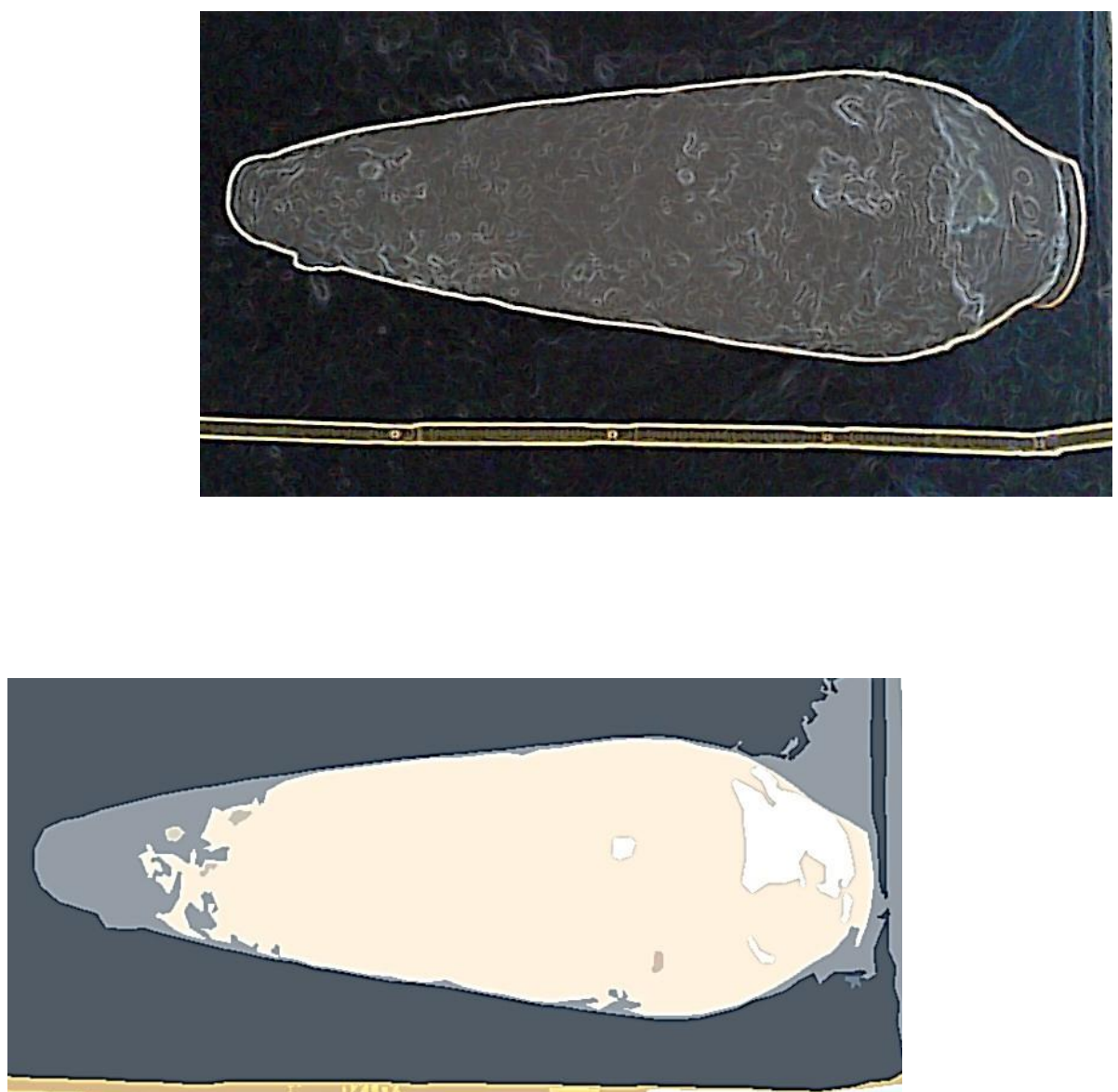

\section{C- Digital Optical Microscope:}

Digital Optical Microscope used to investigate the sample from the Amphorae surface with an uncrossed Nichols and b crossed Nichols filters. The sample appears in dark reddish brown color, it has medium 
texture or medium grain size, appear clearly white thin layer of salts efflorescence over the surface, there are many inhomogeneous organic and inorganic additives (Pic. No. 6,7,8,9,10). 
INTERNATIONAL JOURNAL OF

MULTIDISCIPLINARY STUDIES IN ARCHITECTURE

AND CULTURAL HERITAGE

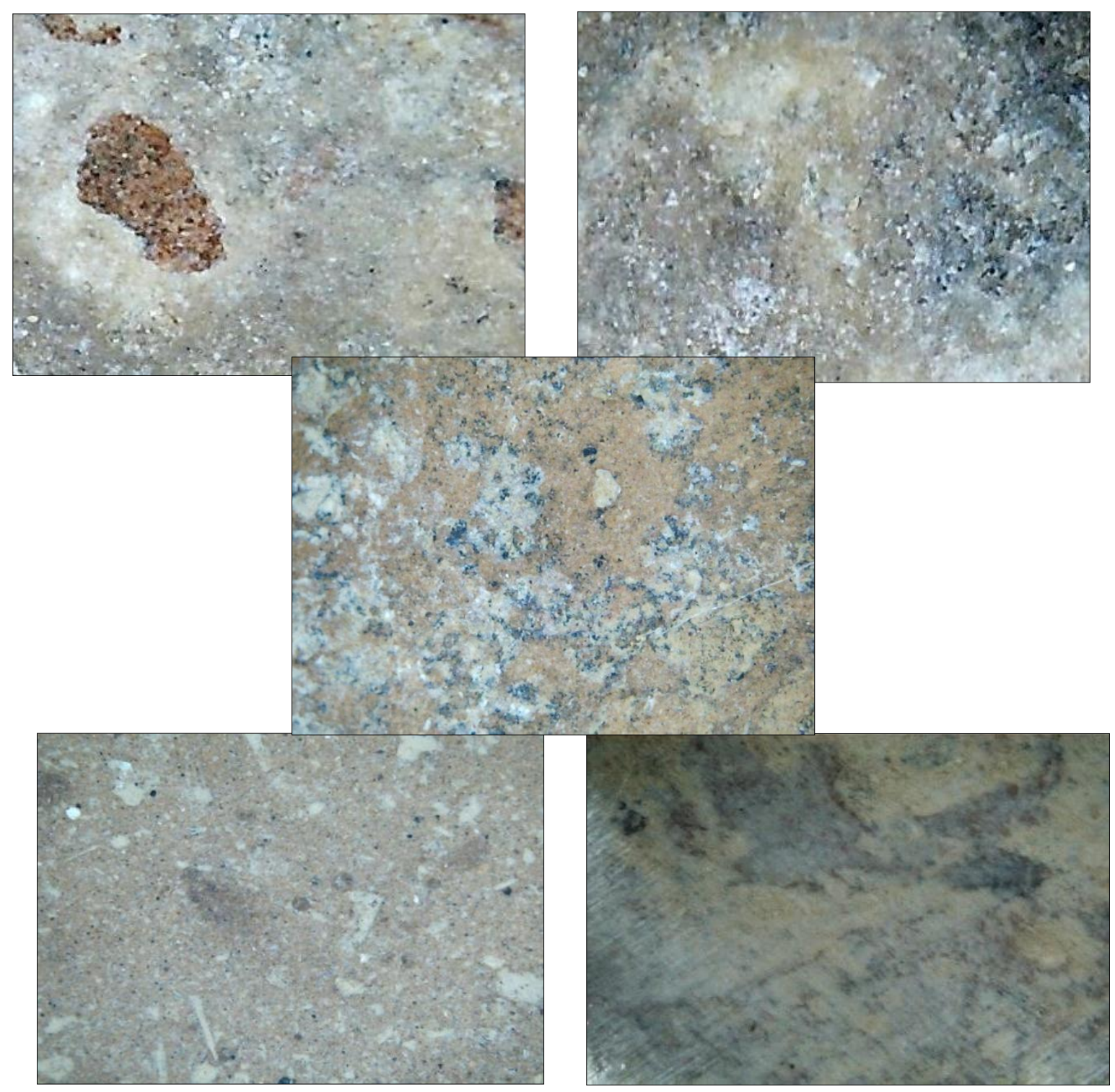


Pic.No. $6,7,8,9,10$ Show the surface of Archaeological pottery Amphorae under the digital microscope, appears the dust, dirt layer and salt efflorescence on the whole degraded surface which is medium coarse or roughness.

\section{D-Scanning Electron Microscope equipped with the Energy DispersiveX-Ray (SEM-EDX) system:}

This method investigated two samples from the surface and from the white layer on it. That SEM Model Quanta 250 FEG (Field Emission Gun) attached with EDX Unit (Energy Dispersive X-ray Analyses), with accelerating voltage

30 K.V., magnification $14 x$ up to 1000000 and resolution for Gun.1n). (Gualtieri, S., 2011) (Santacreu, D., 2014) (White, H., et all, 2015).

By investigating two studied samples, the first is from the Amphorae body, and the second is from the white layer on it, in different magnification resolution range (x. 1000), Micro morphological, and micro structural characteristics, and micro Chemical analyses of surface details, also different components like organic incompletely fired and inorganic additives are detected by Scanning Electron Microscope (SEM) equipped by microprobe (EDX) (Pict. No. 11a,b$12 a, b)$, and the body matrix is medium grain size. 
size.
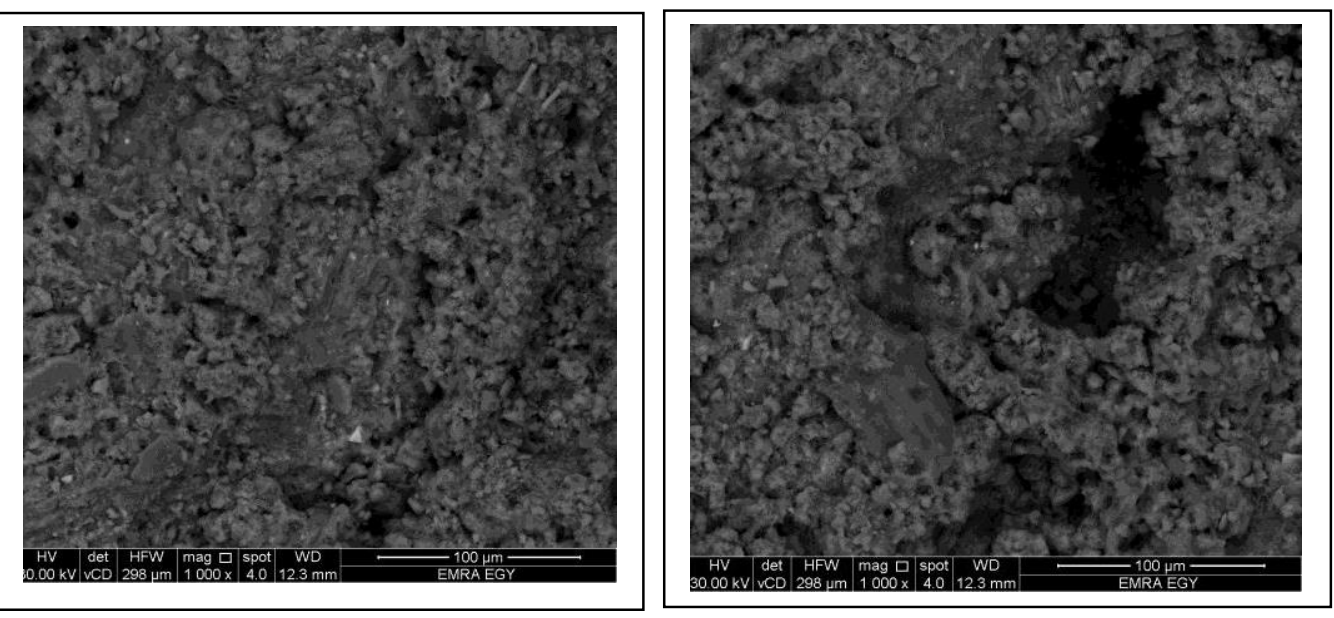

Pic.No. 11a,b 

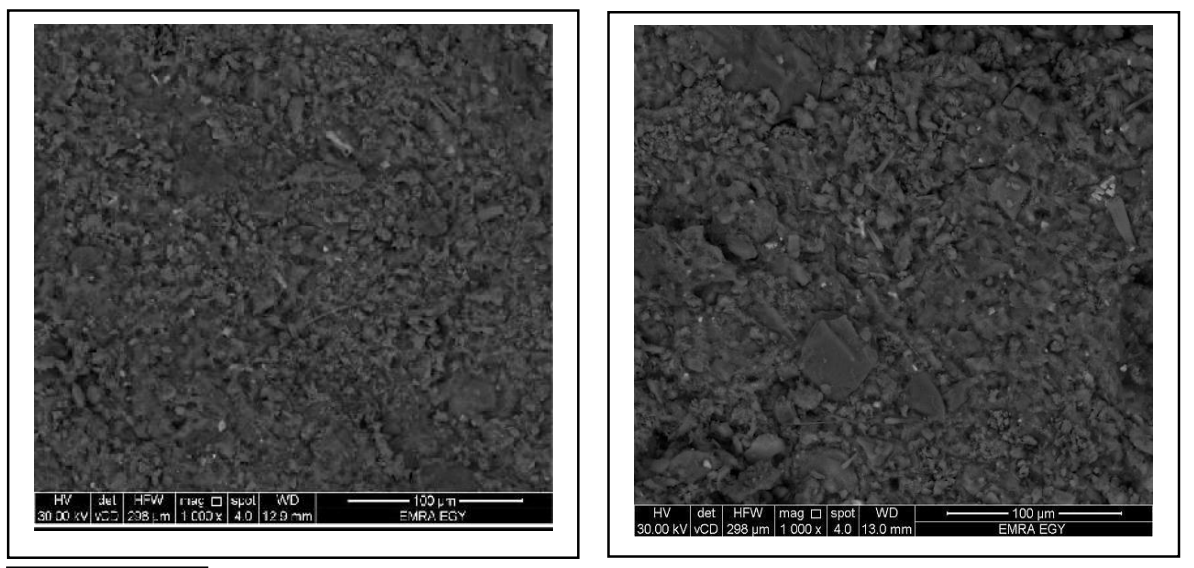

Pic.No.

12 a,b

Pic.No. 11a,b-12a,b in magnification (x. 1000) show the details of Archaeological pottery Amphorae surface under (SEM-EDX) microscope,Pic. $11 \mathrm{a}, \mathrm{b}$ appears the microstructure of the body matrix which is medium grain size, contains organic and inorganic additives. Pic. 12a,b appears the dust and dirt layer and salt efflorescence in fine grains on the whole degraded surface.

\section{2-1 Different Analysis Methods}

\section{3- A-X-Ray Diffraction (XRD) analysis:}

4-

5- This method used to recognize the crystalline components in the 
studied pottery Amphorae sample body as the first one, the second is from the white layer on the surface, Those give two Chart, (Charts No. 1,2$)$.

6- In the Chart No.1, The sample from Amphorae body as the first one contains high percent of iron oxide (quartz) $\mathrm{SiO}_{2}$, in addition to Anorthite mineral (Calcium Aluminium Silicate) $\mathrm{Ca} \mathrm{Al}_{2} \mathrm{Si}_{2} \mathrm{O}_{8}-\mathrm{a}$ high percentage of Halite (salt of Sodium Chloride).

7- In the Chart No.2, The sample from the white layer on the surface, it contains pure Calcium Carbonate as a salt in percent $81.2 \%$, in addition to quartz $18.8 \%$ from the burial soil. 
INTERNATIONAL JOURNAL OF

MULTIDISCIPLINARY STUDIES IN ARCHITECTURE

AND CULTURAL HERITAGE

VOLUME 2, ISSUE 1, 2019, $31-53$.

www.egyptfuture.org/ojs/

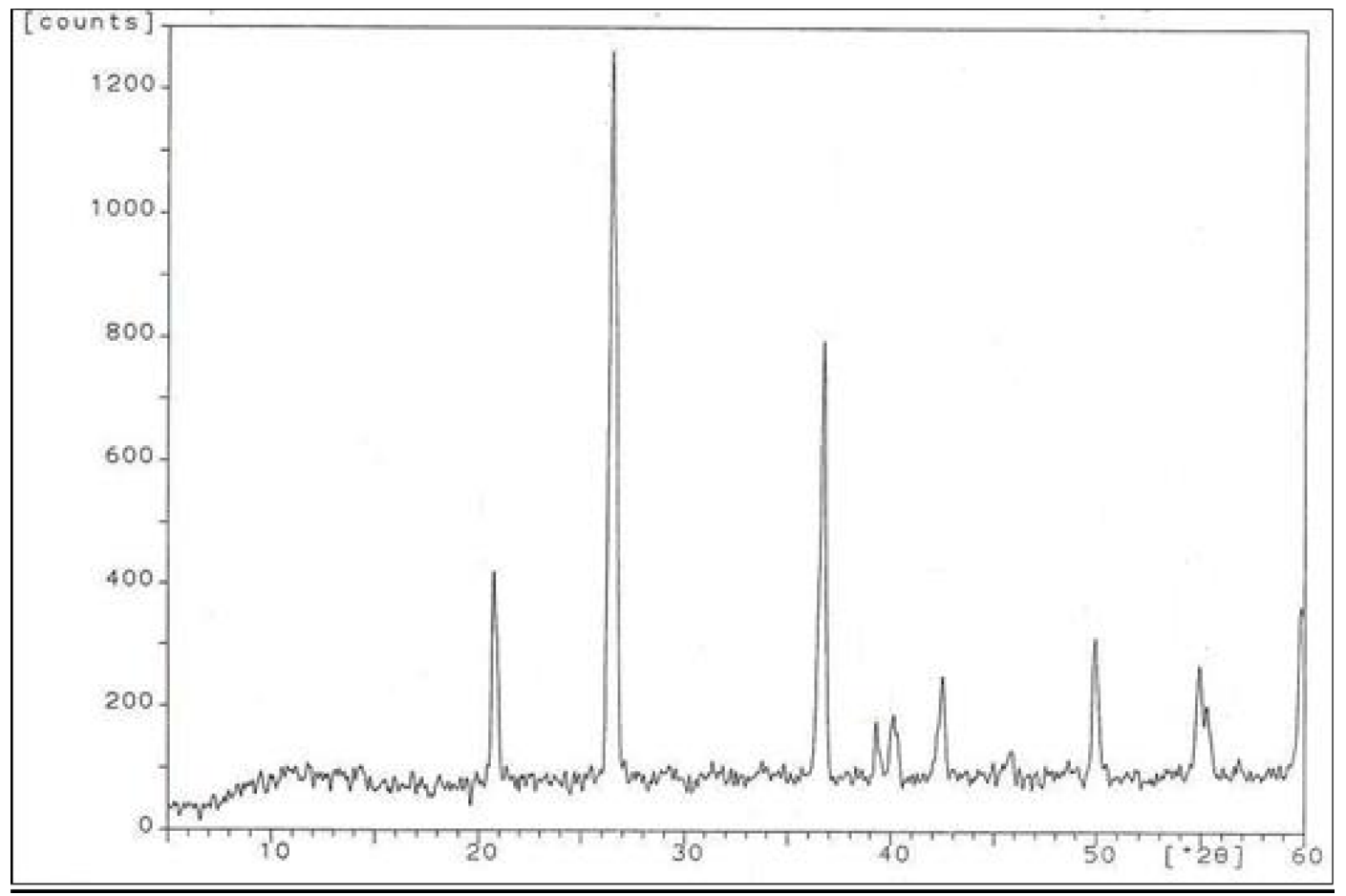




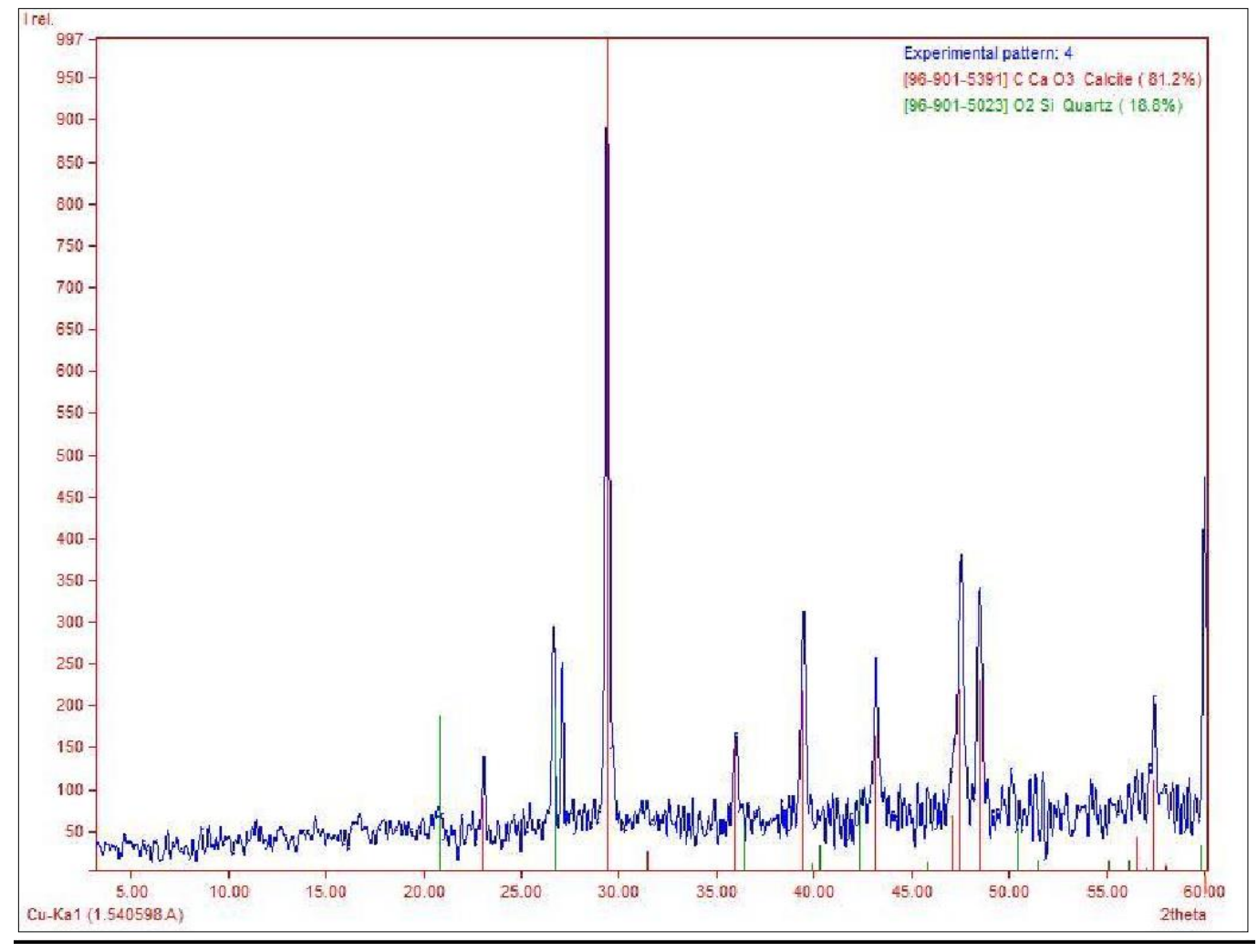

\section{Charts No. 1.2 show X-Ray Diffraction (XRD) analysis Charts} from Amphorae body as the first one, and from the white layer on the surface as second sample.

\section{B- Differential Thermal Analysis (DTA):}

The changes which happened to the clay matrix during firing 
process has strong related to Differential Thermal Analysis (DTA), the formation of the hydrated phases can be monitored (Karatasios, 2014), the sample of Archaeological pottery Amphorae was analyze by Differential Thermal Analysis (DTA), and from the relation between decomposition degree of the sample and component stability (Chart No. 3), from the result we reachedthat; the Archaeological pottery Amphorae was fired at around $800-850 \mathrm{C}^{\circ}$, it considered good firing temperature, but the deterioration happened from the effects of surrounding environmental circumstances. 


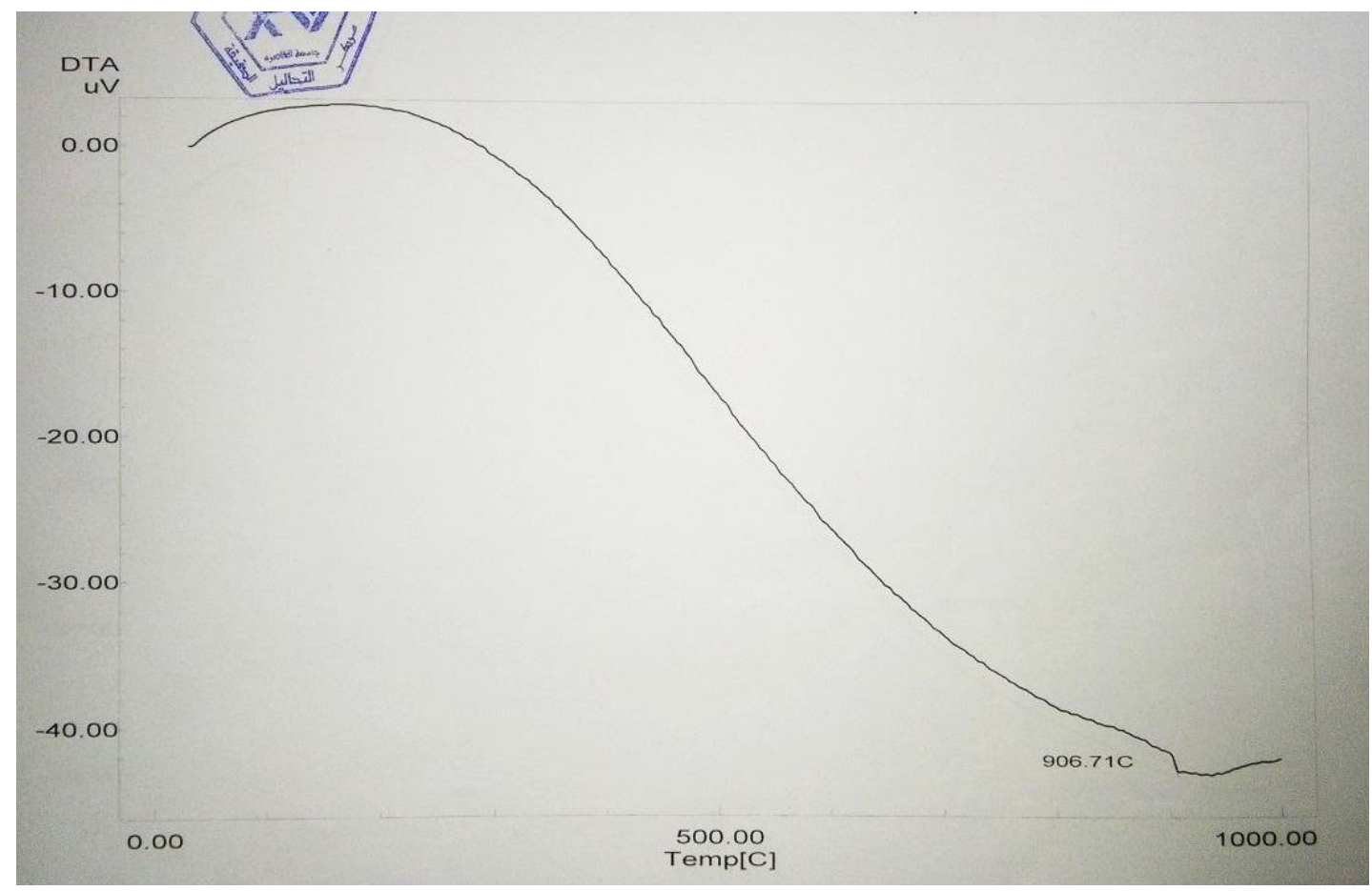

Chart No. 3 shows Differential Thermal Analysis (DTA) analysis from Amphorae body, which was fired at around $800-850 \mathrm{C}^{\circ}$.

\section{2-1 Cleaning and salt removal}

\section{Cleaning}

The Archaeological pottery Amphorae is not decorated or glazed; it is cover with hard layer mixed of dust, dirt and salt crystalline of pure 
Calcium Carbonate. It is best to use mechanical or physical cleaning methods (Appolonia, 2000) as possible as. Since visual examination by eye, Digital Optical Microscope and SEM indicated that the object is almost durable, but extensively damaged, and it is porous, cracked, missing small parts from its base. It is not advice to use chemicals cleaning except in necessary case. It notes that the high-fired pottery objects generally have good resistance to chemical cleaning more than low fired ones. If it necessary it might be used distilled water which is one of strongest polar solvent to dissolve dirt and soluble salt, which has no side effects. The ethyl alcohol with water 1:1 gave good

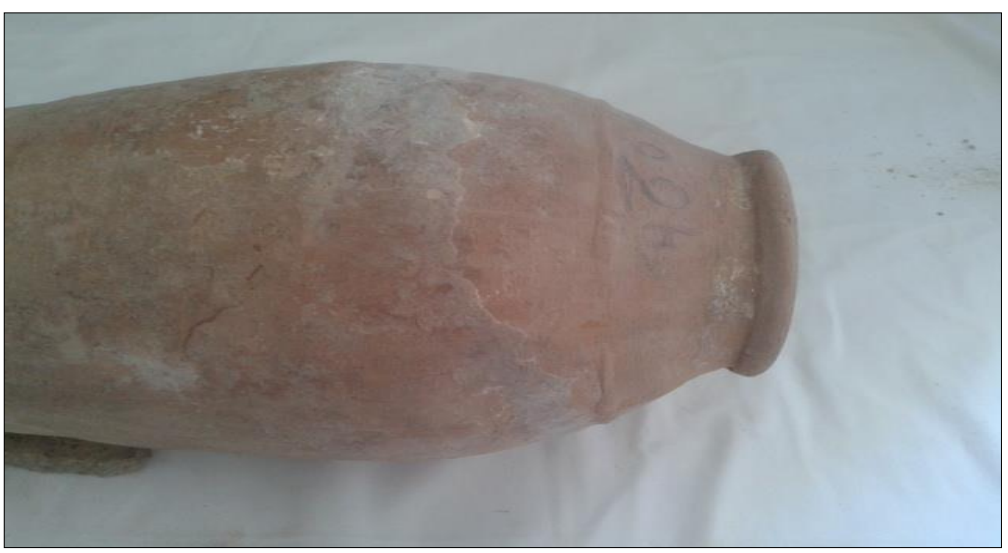

result to remove burial sediments which covered the amphorae surface (Pic. No. 13).

\section{Salt removing}


After finished mechanical cleaning of salt to extent limit, An alkaline solution can use for salt removing like chelating agent tetra sodium salt of EDTA [Na3 EDTA] Ethylene-di Amin Tetra Acetic Acid was applied to remove salt and weathering crusts on the amphorae surface. The solution $(3 \%$, then $5 \%$ concentration and $11.5 \mathrm{pH})$ was applied with tissue paper poultices, were replaced every 20 minutes until salts removed. To ensure that the chelation completely occurred and the crusts are softened (Paul, 1978) (Pessoa, J.C., 1996) (Linnow. k., et all 2007) always wet the place of treatment with distilled water before and after removing process, to decrease the side effects of chemicals, Then used mechanical removing on the soft crusts by using fine brushes and any suitable helping tools (Pic. No. 14).

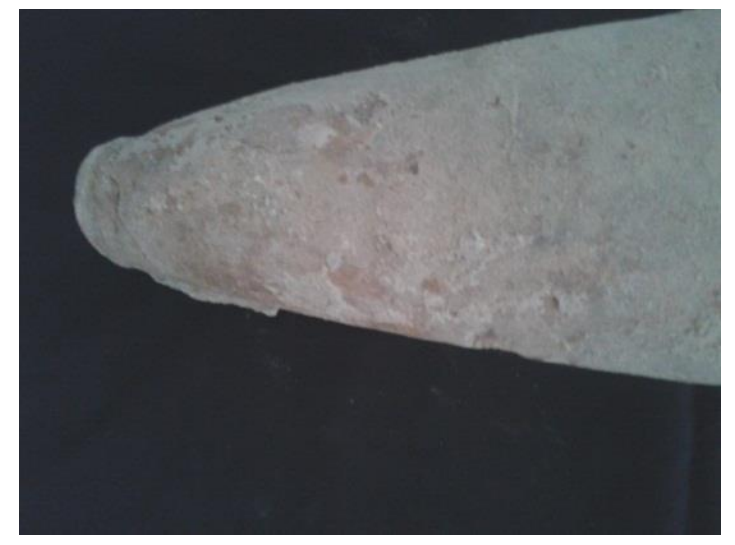

\section{2-1 Consolidation}


The selected Archaeological pottery Amphorae were excavated from the ground and have suffered of damage through the absorption of soluble salts and subsequent cycles of crystallization, dissolution, re-crystallization, re- dissolution, thus consolidation of these Archaeological pottery Amphorae was necessary to strengthen their structure and prevent the effect of moisture and relative humidity during the coming storage or exhibition stage (Pic. No. 15,16).
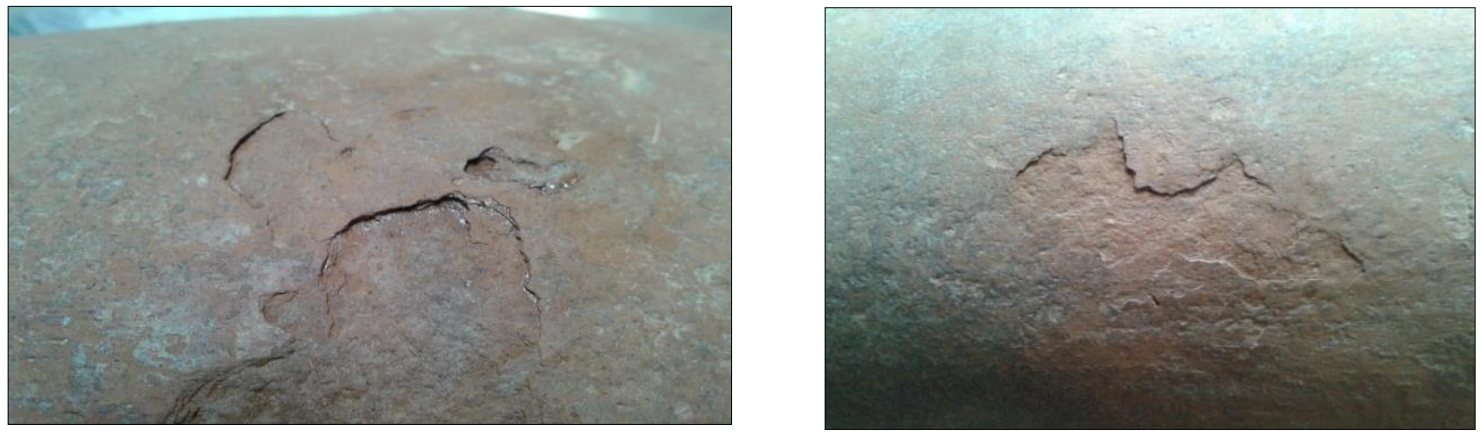

In addition successful consolidation strength the amphorae to be handled safely, and give it long life. Ethyl Silicate is one of the important inorganic consolidates based on alkaline potassium and sodium silicate, it is contains Silicic acid ethyl ether $70 \%$ and $30 \%$ Solvent, its Viscosity $3.3 \mathrm{c}$ set at $25 \mathrm{C}^{\circ}$, Specific weight 0.970 at $15 \mathrm{C}^{\circ}$ and Flammability $17 \mathrm{C}^{\circ}$. It appropriate for consolidate this amphorae which composed silica based, this consolidant preserve the appearance of the material to which it has been applied without changes, because it has good penetration, and it is biological and 
chemical stable and not give a viscose surface (Horie 1987, Newton and Davison 1989, Sease1994). The consolidant is dropped onto the flaked surface (Eleston, M. 1990). On two followed applications (Pic. No. 17).

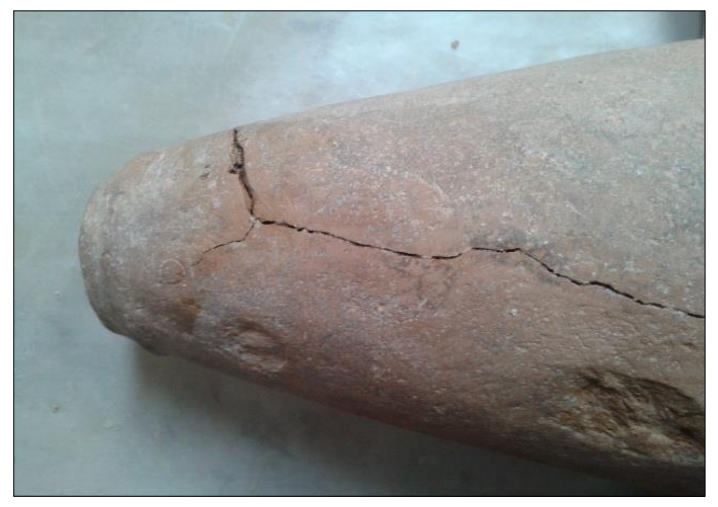

Archaeological Pottery Amphorae subjected to many deteriorate factors; the materials and techniques used for cleaning, consolidation, and replacement must be evaluated and experimented before used, especially if it new materials, and choose the more suitable to the object state. Mechanical method always is the best, and has no any side effects.

EDTA [Na3 EDTA] was successfully removed the salt encrustations on the Amphorae surface especially calcium carbonate, with kept the place of treatment wet before and after removing process with distilled water, to decrease the side effects of chemicals. 
Replacement materials have wide ranges, it must be simple to use and apply, and sometimes the lost part is a very big area and needs supporting materials. But some of these materials have disadvantage of reaction with the object matrix, which accelerates some deteriorate reactions. So the reconstruction materials must have resistant to all surrounding environment and the long time which will life.

\section{4- Conclusion:}

Documentation is the first treatment step followed by visual examination to Archaeological Pottery Amphorae, then come clean step to remove any foreign materials from the surface like soil or deposits and encrustation. The choosing of cleaning methods depends on the nature of both the pottery and dirt. Not to remove patina this is a protective action. Removal can become more difficult if the object is low-fired, less durable, unglazed and previously restored.

\section{5- References:}

1) A Standard for Pottery Analysis in Archaeology, Prehistoric Ceramics Research Group, Medieval Pottery Research Group, Study Group for Roman Pottery, 2015. 
2) Appolonia, L., lectures in ceramic, Euro-Med course on materials $\&$ technologies for the conservation of cultural heritage consisting of ceramic, Perugia, Italy, sep.28 th - oct.4 th, 2000.

3) Devries, B., The Conservation of Vandalized Nodding Figure, Royal Pavilion, Brighton, in: ICOM committee for conservation 11 th triennialMeeting, Edinburgh, Scotland, 1-6 Sep., 1996, vol .I, П.

4) Horie, C.V., Materials for conservation, organic consolidates adhesives and coatings, Butter worth \& Co. (publishers) Ltd., 1987. 5) Karatasios I, et all, The second life of Ceramics: a new home in a lime environment, In: M Martinón-Torres (Ed.), Craft and Science: International perspectives on archaeological Ceramics, (2014).

6) Linnow. K., Halsberghe, L. and Steiger, M., Analysis of Calcium acetate efflorescence formed on Ceramic tiles in a Museum environment, Journal of cultural heritage, 2007, (8):44-52.

7) Newton, R. and Davison, S., Conservation of glass, Butterworth, London, 1989.

8) Pessoa, J.C., Removal and analysis of soluble salts from Ancient tiles, in: studies in conservation, 1996, vol.41 (3).

9) Paul, A. Influence of complexing agents and nature of the buffer solution on the chemical durability of glass. Part I., Theoretical 
discussion, Journal of Glass Technology, 1978, (19): 162-165.

10) Sease, C., Conservation manual for the field Archaeologist, 3rd edition, California, 1994.

11) Eleston, M. (1990) Technical and esthetic considerations in the conservation of ancient ceramics and terracotta objects in the J. Paul Getty Museum: five case studies. Studies in conservation, 35 (2): 69-80.

12) Buna, Z., et all, ENGINEERING CAD TOOLS IN DIGITAL ARCHAEOLOGY, 2014. 